\begin{tabular}{|c|c|c|c|c|}
\hline Indication & $\begin{array}{l}\text { SB bleeding } \\
(n=94)\end{array}$ & $\begin{array}{l}\text { ?IBD/IBD reassessment } \\
(\mathrm{n}=84)\end{array}$ & $\begin{array}{l}\text { ?SB neoplasia } \\
(\mathrm{n}=15)\end{array}$ & $\begin{array}{l}\text { Others } \\
(n=11)\end{array}$ \\
\hline $\begin{array}{l}\text { No. of CEs where findings differed } \\
\text { between heads }\end{array}$ & $27(28.7 \%)$ & $30(35.7 \%)$ & $2(13.3 \%)$ & $1(9.1 \%)$ \\
\hline $\begin{array}{l}\text { Mean numerical difference in findings } \\
\text { between heads (range) }\end{array}$ & $3.4(0-16)$ & $4.3(0-39)$ & $4(3-5)$ & 3 \\
\hline $\begin{array}{l}\text { No. of CEs where differences were } \\
\text { clinically significant }\end{array}$ & $\begin{array}{l}17(18.1 \%) \\
\text { In } 1 \mathrm{CE} \text {, no. of findings was same but type was } \\
\text { significantly different }\end{array}$ & $\begin{array}{l}11(13.1 \%) \\
\text { In } 1 \mathrm{CE} \text {, no. of findings was same but type } \\
\text { was significantly different }\end{array}$ & $2(13.3 \%)$ & $0(0 \%)$ \\
\hline Details & $\begin{array}{l}\text { Findings missed by single-headed CE: } 16 \\
\text { 1. Angioectasias (5) } \\
\text {-SB inflammation (7) } \\
\text { - Oesophagitis (2) } \\
\text {-SB masses (2) } \\
\text { Difference in findings changed assessment of extent/ } \\
\text { severity: } 1 \text { (angioectasias) }\end{array}$ & $\begin{array}{l}\text { Missed findings: } 5 \\
\text { - In all, signs of active inflammation missed } \\
\text { by single-headed CE } \\
\text { Difference in findings changed assessment of } \\
\text { extent/severity: } 6\end{array}$ & $\begin{array}{l}\text { Missed findings: } 1 \text { polypoid mass, } \\
1 \text { SB diverticulum }\end{array}$ & na \\
\hline
\end{tabular}

overall conclusion/diagnosis were compared between single and double-headed examinations.

Results 211 CE examinations were performed. 7 failed to reach the SB; 204 cases were analysed. Indications were (a) SB bleeding; (b) ?SB inflammation or reassessment of known inflammatory bowel disease (IBD); (c) ?SB neoplasia including suspicious radiological imaging and (d) others e.g. ?coeliac disease. Results are presented in table 1 .

Overall, use of two CE heads impacted the diagnosis in 30/ $204(14.7 \%)$ of cases in our cohort.

Conclusions The use of double-headed CE provides more information which has the potential to change clinical diagnosis and therefore management. Therefore, the routine adoption of double-headed CE in SB assessment should be considered.

\section{PTU-129 INDICATIONS AND OUTCOMES OF COLONOSCOPY IN THE VERY ELDERLY PATIENTS}

Abdulkani Yusuf*, Ben Ayeboa-sallah, Mustafa Agbna, Khai Leow, Holly Tucker, Arun Jeevagan, Phil Mayhead. East Sussex Healthcare NHS Trust, Eastbourne, UK

\subsection{6/gutjnl-2019-BSGAbstracts. 118}

Introduction Colonoscopy is the investigation of choice for lower gastrointestinal symptoms. We wanted to review the indications and outcomes of colonoscopy in the very elderly patients at a district general hospital.

Methods We retrospectively reviewed all patients $\geq 85$ years who underwent colonoscopy from June 2016- June 2018using using our endoscopy reporting system (Endobase). We collected data on demographics, indications for the procedure, bowel preparation type and success, sedation and analgesia rates, caecal intubation rates, findings and complication rates.

Results From June 2016-June 2018, there were 243 patients $\geq 85$ years who underwent colonoscopy, mean age 87.0 years (range 85-96), males 41.8\%, females 51.9\%. The commonest indications were: change of bowel habit $(\mathrm{n}=75$, $30.1 \%)$, anaemia $(n=53,21.8 \%)$, abnormal imaging $(n=30$, $12.3 \%)$, rectal bleeding $(n=25,10.3 \%)$, polyp surveillance $(\mathrm{n}=18,7.4 \%)$, polypectomy $(\mathrm{n}=16,6.6 \%)$, colon cancer surveillance $(\mathrm{n}=10,4.1 \%)$, IBD surveillance $(\mathrm{n}=2$, $0.4 \%)$, and other $(\mathrm{n}=9,3.7 \%)$. All patients went thorough bowel preparation with PEG solution with excellent or adequate results in 209 (86.0\%), and inadequate in 34 (14.0\%). Fentanyl was used in 175 patients (72.0\%, average dose $43.2 \mathrm{mcg})$, Pethidine in $17(7.0 \%$, average dose 26.5 $\mathrm{mcg}$ ), Entonox in 27 patients (11.1\%), and Midazolam in 184 patients $(75.7 \%$, average dose $1.84 \mathrm{mg})$. Unadjusted caecal intubation rate was $84.4 \%(n=205)$, rising to $88.7 \%$ when adjusted for obstructing lesions. Commonest causes for incomplete procedure $(\mathrm{n}=38)$ were: Obstructing lesions $(\mathrm{n}=12,31.6 \%)$, inadequate bowel preparation $(\mathrm{n}=7$, $18.4 \%)$, patient intolerance $(n=6,15.7 \%)$, and diverticulosis $(\mathrm{n}=5,13.2 \%)$. Cancer was found in 21 patients $(8.6 \%)$. Polyps of any size were found in 90 patients (37.0\%), but significant polyps (polyps $\geq 10 \mathrm{~mm}$ ) were found in 42 patients $(17.3 \%)$ with average polyp size of $20.7 \mathrm{~mm}$ (range 10-80 $\mathrm{mm})$. Other significant findings included colonic diverticulosis in $(n=147,60.5 \%)$, haemorrhoids $(n=73,30.0 \%)$, and IBD $(n=4,1.6 \%)$. Three patients developed peri-procedure complications: Oxygen desaturation and tachycardia $(n=1$, $0.4 \%)$, hypotension $(n=1,0.4 \%)$ and chest pain and reduced consciousness, requiring reversal agent $(n=1,0.4 \%)$. There were no significant bleeding or perforation reported for this cohort.

Conclusions Overall colonoscopy seems to be safe in the extreme ages with low complication rates. The caecal intubation rate was lower than the BSG/JAG recommended cut off $90 \%$, and this was mostly attributable to inadequate bowel preparation and obstructing lesions. If both of these limitations are adjusted for, the completion rate was $91.5 \%$. 